\title{
Temperature Effects On The Hydrogen Content And Passivation Of Silicon Surface Coated With $\mathrm{Sio}_{2}$ And Sin Films
}

\author{
C. U. Ike, \\ Department of Physics and Industrial Physics Nnamdi Azikiwe University, Awka, Nigeria.
}

\begin{abstract}
A detailed comparison of the passivation quality and its dependence on the low and high temperature anneals has been carried out for various promising $\mathrm{Si}$ surface passivation schemes. The passivation schemes investigated include; conventional furnace oxide (CFO) rapid thermal oxide (RTO), belt line oxide (BLO), plasma deposited oxide (PDO), SiN deposited by plasma enhanced chemical vapour deposition (PECVD). The passivated low resistivity $(1 \Omega-\mathrm{cm})$ p-type silicon samples were subjected to three annealing treatments; $400^{\circ} \mathrm{C}$ in forming gas $(\mathrm{FGA}), 730^{\circ}$ in air and $850^{\circ} \mathrm{C}$ in air to stimulate heat-treatments which were typically used for contact anneal, font ohmic contacts, and back surface field formation respectively for screen printed silicon solar cells. It was found that the passivation quality of PDO, SiN, RTO and CFO single layers improved significantly after the $400^{\circ} \mathrm{C} \mathrm{FGA}$ and $730^{\circ}$ thermal cycles with RTO resulting in the lowest surface recombination velocities $\left(\mathrm{S}_{\text {eff }}\right)$ of 154 and $405 \mathrm{~cm} / \mathrm{s}$, respectively. Silicon wafers coated with belt oxide (BLO and BLO/SiN) did not show any improvement in $\left(\mathrm{S}_{\text {eff }}\right)$ which remained at $5000 \mathrm{~cm} / \mathrm{s}$ due to the inferior quality of BLO formed compressed air. The oxide/nitride stack passivation was found to be far superior to single-layer passivation resulting in $\left(\mathrm{S}_{\text {eff }}\right)$ of $70 \mathrm{~cm} / \mathrm{s}$ for the $\mathrm{RTO} / \mathrm{SiN}$ scheme after the two high temperature anneals $\left(850\right.$ and $\left.730^{\circ} \mathrm{C}\right)$. A combination of reduced hydrogen content and very low $\mathrm{S}_{\text {eff }}$ in the RTO/SiN stack suggested that the release of hydrogen from SiN during the anneal further passivated the RTO/Si interface underneath.
\end{abstract}

Key words: - Temperature effect, hydrogen content, passivation, $\mathrm{Si}_{-} \mathrm{SiO}_{2}$ and $\mathrm{Si}$-SiN

\section{INTRODUCTION}

Screen printed (SP) contact technology is simple, low cost, and manufacturable but screen printed Silicon solar cell efficiency is low due to inherent loss mechanism (Nijis et al, 1994 and Dashi et al, 1996). In order to improve the efficiency of the SP cells, the losses due to higher grid line shading, contact resistance, heavily doped emitter, and very high back surface recombination velocity due to the full metal back, must be minimised. Since the back surface recombination can increase the dark saturation current density of solar cells, the application of an effective back surface passivation could significantly improve the cell performance; this would require a reduction in the back metal coverage coupled with excellent passivation of the non contacted regions at the back.

In addition, as thinner materials are used to reduce the cost, the back-side recombination could have an even bigger impact on the cell performance. Figure 1 shows that, if a metal grid is used on the back with the non contacted back surface fully passivated to produce an $S_{\text {eff }}$ of $100 \mathrm{~cm} / \mathrm{s}$, a thinner photovoltaic $(\mathrm{PV})$ grade material

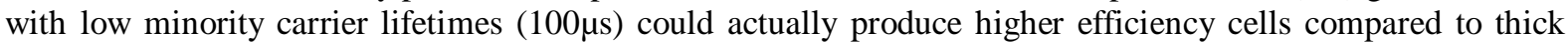
cells. This provided the motivation for investigating the low cost manufacturable back passivation schemes subjected to SP solar cell processing steps. The SP solar cell processing steps. The SP solar cell processing involves a 2 min back surface field (BSF) formation at $850^{\circ}$ followed by a $730^{\circ} \mathrm{C}$ front contact firing for $30 \mathrm{~s}$ and a $20 \mathrm{~min}$ forming gas anneal at $400^{\circ} \mathrm{C}$.

\section{EXPERIMENTAL}

$1 \Omega$-cm, chemically polished $\mp$-type (100), float zone (FZ) wafers were used as substrates which were cleaned in 1:1:2 $\mathrm{H}_{2} \mathrm{SO}_{4}: \mathrm{H}_{2} \mathrm{O}_{2}: \mathrm{H}_{2} \mathrm{O}$ for $5 \mathrm{~min}$ followed by a $3 \mathrm{~min}$ rinse in deionized (DI) water. This was followed by a clean in 1:1:2 $\mathrm{HCl}: \mathrm{H}_{2} \mathrm{O}_{2}: \mathrm{H}_{2} \mathrm{O}$ for $5 \mathrm{~min}$ and a 3 min rinse in $\mathrm{D} 1$ water rinse. The thin oxides (100A) were grown by RTP, BLP and CFP. In addition, PECVD $\mathrm{SiO}_{2}$ or PDO was deposited at $250^{\circ} \mathrm{C}$ with $20 \mathrm{~W}$ power while another set of oxidized samples were coated with PECVD $\mathrm{SiN}$ at $300^{\circ} \mathrm{C}$ with $30 \mathrm{~W}$ power to form the oxide/nitride stacks. One RTO/SiN sample was coated with $900 \AA ̊$ of PDO to form a double-layer AR coating. The quality of each passivation scheme was assessed by determining surface recombination velocity (SRV) by the transient photoconductive decay (PCD) technique. The effective PCD lifetime of the minority carriers was converted to an effective surface recombination velocity $\left(\mathrm{S}_{\text {eff }}\right)$ according to Schroder, (1997)

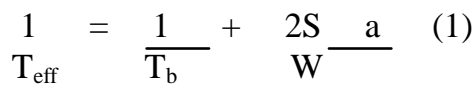


Where $T_{\text {eff }}$ is the effective minority carrier lifetime, $T_{b}$ is the bulk minority carrier lifetime, $S$ is the effective surface recombination velocity, and $\mathrm{W}$ is the wafer thickness.

Since FZ wafers had bulk lifetime $\left(T_{b}\right)$ in excess of $1 \mathrm{~ms}$, the value of $S_{\text {eff }}$ in this study was determined by

$$
\frac{1}{T_{\text {eff }}}=\frac{2 \mathrm{~S}}{\mathrm{~W}}
$$

which is valid for very high or infinite carrier lifetime and good SRV (Schroder 1997). Thus, the $S_{\text {eff }}$ values represents a maximum or worst case scenario. All the effective minority carrier lifetimes were measured in the low level injection regime between $2 \times 10^{14}$ and $1 \times 10^{15}$.

Measurements were performed at room temperature to determine the hydrogen content of various passivation schemes. The samples analysed by these measurements included (i) SiN without anneal, after forming gas anneal (FGA) at $400^{\circ} \mathrm{C}$ and after belt line furnace anneals at 730 and $850^{\circ} \mathrm{C}$ in air (ii) $\mathrm{RTO} / \mathrm{SiN}$ stack without anneal at $730^{\circ} \mathrm{C}$ and $850^{\circ} \mathrm{C}$ in air.

\section{GROWN SINGLE LAYER AND STACK PASSIVATION}

The $S_{\text {eff }}$ for all the single-layer oxides, without anneal, was found to be high, ranging from 550 to $570 \mathrm{~cm} / \mathrm{s}$ for RTO and CFO, respectively and $5000 \mathrm{~cm} / \mathrm{s}$ each, for BLO, PDO and SiN. The very high $\mathrm{S}_{\text {eff }}$ for $\mathrm{PDO}$ and $\mathrm{SiN}$ was attributed to very high $\mathrm{D}_{\mathrm{it}}$ at the dielectric/Si interface due to the damage caused by the reacting species during deposition. High $\mathrm{S}_{\text {eff }}$ for BLO was due to the poor $\mathrm{S}_{\mathrm{i}} / \mathrm{S}_{\mathrm{i}} \mathrm{O}_{2}$ interface formed in the air instead of pure oxygen. Relatively lower $S_{\text {eff }}$ for the RTO and CFO suggestd a higher quality interface between $\mathrm{RTO} / \mathrm{Si}$ and CFO/Si. For the stack passivation schemes, $\mathrm{S}_{\text {eff }}$ was found to decrease with $\mathrm{SiN}$ deposition on most thin $\mathrm{S}_{\mathrm{i}} \mathrm{O}_{2}$ layers with $\mathrm{S}_{\text {eff }}$ of $167 \mathrm{~cm} / \mathrm{s}$ for $\mathrm{RTO} / \mathrm{SiN}$ stack.

\section{EFFECT OF $400^{\circ} \mathrm{C}$ FGA ON SINGLE-LAYER AND STACK PASSIVATION SCHEMES.}

Here the low temperature forming gas anneal (FGA) at $400^{\circ} \mathrm{C}$ for $20 \mathrm{~min}$ often used to anneal contacts in solar cells, improved the passivation quality of all the passivation schemes except for BLO. For example, the effective surface recombination velocity, for RTO alone decreased from 550 to $154 \mathrm{~cm} / \mathrm{s}$ after the $400^{\circ} \mathrm{C}$ anneal. There were some improvements in both the CFO and PDO due to the FGA - induced hydrogen passivation of the interface.

On stack passivation, the effective surface recombination velocity of BLO/SiN stack remained very high $(>4000 \mathrm{~cm} / \mathrm{s})$ after FGA. A significant improvement was obtained in the RTO/PDO and RTO + FGA passivation indicating that PDO deposition does not hurt RTO/Si interface underneath. The RTO/SiN and CFO.SiN $N_{o}$ also showed a further reduction in $S_{\text {eff }}$ when annealed in forming gas with the $\mathrm{S}_{\mathrm{i}} \mathrm{N}$ cap resulting in $\mathrm{S}_{\text {eff }}$ values of 68 and $70 \mathrm{~cm} / \mathrm{s}$ respectively. The reduction in $S_{\text {eff }}$ with forming gas anneal was consistent with the observation of other researchers such as Lauinger et al 1995, Narasimha and Rohatgi, 1998.

\section{EFFECT OF $730^{\circ} \mathrm{C}$ ANNEAL ON SINGLE-LAYER AND STACK PASSIVATION SCHEMES}

The $730^{\circ} \mathrm{C}$ in a belt lamp furnace improved the passivation quality of all the passivation schemes except BLo, which remained unchanged. The $\mathrm{S}_{\text {eff }}$ of PDO, RTO and CFO single layers decreased by a factor of about $2.7,1.4$ and 1.4 respectively, after the $730^{\circ} \mathrm{C} / 30 \mathrm{~s}$ anneal. The SiN single layer showed improvement by a factor of five (from 5000 to $676 \mathrm{~cm} / \mathrm{s}$ ) due to the passivation of the SiN/Si interface by the release of a significant amount of hydrogen from SiN film.

The passivation efficiency of RTO/PDO stack improved due to the $730^{\circ} \mathrm{C}$ anneal resulting in $\mathrm{S}_{\text {eff }}$ of $451 \mathrm{~cm} / \mathrm{s}$. The BLO/S-iN passivation scheme showed a marginal improvement due to the extremely poor $\mathrm{BLO} / \mathrm{Si}$ interface, which could not be revived by hydrogen injection. On the other hand, the PDO/S-iN, CFO/SiN RTO/SiN passivation schemes showed a reduction in $S_{\text {eff }}$ values by a factor of 9,5 and 3 respectively, as a result of the $730^{\circ} \mathrm{C}$ contact anneal. The decrease in SRV was the result of the release of hydrogen from the SiN coupled with the hydrogen passivation at the RTO/Si interface.

\section{EFFECT OF $850^{\circ} \mathrm{C}$ ANNEAL ON STACK PASSIVATION}

The quality of $\mathrm{CFO} / \mathrm{SiN}$ and $\mathrm{RTO} / \mathrm{SiN}$ were found to be superior to all other passivation schemes in this study after the $400^{\circ} \mathrm{C} \mathrm{FGA}$ and $730^{\circ} \mathrm{C}$ anneals; which mimic the contact anneal and SP contact firing cycles. However, they also need to withstand the AI BSF formation step, which involves $850^{\circ} \mathrm{C} / 2 \mathrm{~min}$ anneal. Therefore these two stacks were subjected to $850^{\circ} \mathrm{C}$ anneals. $850^{\circ} \mathrm{C} / 2 \mathrm{~min}$ anneal of $\mathrm{CFO} / \mathrm{SiN}$ resulted in an $\mathrm{S}_{\text {eff }}$ value of 102 and $81 \mathrm{~cm} / \mathrm{s}$ for RTO/SiN stack. These two values are impressive and compatible with achieving high efficiency cells on this PV grade materials. 


\section{VII. $\quad$ EFFECT OF ANNEALING TIME ON STACK PASSIVATION}

Since $\mathrm{CFO} / \mathrm{SiN}$ and $\mathrm{RTO} / \mathrm{SiN}$ schemes provided better passivation of the silicon surface after the short high temperature anneal, a study was conducted to see the effects of annealing time. The $730^{\circ} \mathrm{C} / 30 \mathrm{~s}$ anneal on $\mathrm{RTO} / \mathrm{SiN}$ stack resulted in a very low $\mathrm{S}_{\text {eff }}$ value of $12 \mathrm{~cm} / \mathrm{s}$, which increased fourfold when the annealing time was increased to $2 \mathrm{~min}$. Also, the $\mathrm{CFO} / \mathrm{SiN}$ stack after $730^{\circ} \mathrm{C} / 30 \mathrm{~s}$ anneal resulted in $\mathrm{S}_{\text {eff }}$ value of $23 \mathrm{~cm} / \mathrm{s}$ and increased twofold as the annealing time increased to $120 \mathrm{~s}$. The $\mathrm{S}_{\text {eff }}$ for RTO/SiN annealed at $850^{\circ} \mathrm{C}$ increased from 30 to $81 \mathrm{~cm} / \mathrm{s}$ when the annealing time was increased from 30 to $120 \mathrm{~s}$. The $\mathrm{CFO} / \mathrm{SiN}$ stack passivation showed the same trend with $S_{\text {eff }}$ varying from 30 to $102 \mathrm{~cm} / \mathrm{s}$ as the $850^{\circ} \mathrm{C}$ annealing time was increased from 30 to $120 \mathrm{~s}$. This suggests that out-diffusion of the hydrogen from the oxide/Si interface as the annealing time increases results in reduction in the passivation quality. Again, it is important to recognise that even though the stack passivation degrades with annealing temperature and time, the final values of $\leq 100 \mathrm{~cm} / \mathrm{s}$ are extremely good for high efficiency solar cells.

\section{CONCLUSION}

The passivation quality of various promising dielectric passivation schemes for low resistivity silicon wafer has been compared. Passivation quality is assessed in terms of SRV before and after 400/30min FGA and 730 and $850^{\circ} \mathrm{C}$ anneals in air. These processes are commonly used for contact anneal, front grid and AI BSF formation of SP solar cells. In addition to single-layer, oxide and nitride films, oxide/nitride stacks are also formed by depositing SiN films on top of thin oxide films to provide antireflection coating for solar cells. In this study it was also found that stack passivation was superior to the counterpart individual films. Higher temperature and longer annealing time could degrade passivation quality. However, by choosing appropriate films and annealing conditions, one could achieve very good surface passivation below $100 \mathrm{~cm} / \mathrm{s}$ on $1 \Omega$-cm ptype silicon. It was found that $400^{\circ} \mathrm{C} / 20 \mathrm{~min}$ anneal improved the passivation quality of all the films. Likewise 730 and $850^{\circ} \mathrm{C}$ anneals improve passivation, but the best results were obtained for a shorter anneal time in the order of 30s. Unlike the other passivation schemes, the RTO/SiN stack was not only able to withstand $850^{\circ} \mathrm{C} / 2 \mathrm{~min}$ anneal but was actually improved as a result of that. This is because the hydrogen released from the $\mathrm{SiN}$, during this anneal, passivates the RTO/Si interface.

\section{REFERENCES}

[1] Basore, P., (1990). IEEE Trans. Electron Device, ED - 37, 337

[2] Chen, Z.. Yasutake K., Doolittle A, and Rohatgi A., (1993). Appl. Phys. Lett., 63, 2117

[3] Doshi P., Mejia J., Tate K. and Rohatgi, (1996). IEEE Electron Device Lett., EDL - 17, 404

[4] Landford W. A. and Rand M. J, (1978). Appl. J. Phys., 49, 2473

[5] Lauinger T., Schmidt J., Aberle A. and Hezel R., (1995). In proceedings of the $13^{\text {th }}$ European Photovoltaic Solar Energy Conference, Nice, France, European Commission, Eurosolar and The European Association of Solar Association of Solar Energy, pp. 1291 - 1294

[6] Narasimha, S. and Rohatgi, A., (1998). Appl. Phys. Lett., 72, 1872

[7] Nijis J., DEmesmaeker E., Szlufcik J., Poortmans J., Frisson L., De Clercq K., Ghannam M., Mertens R., and Overstraeten R. V. (1994). In proceedings of the $1^{\text {st }}$ World Conference on Photovoltaic Energy Conversion, Hawaii, Vol. 2, IEEE Electron Device Society, pp. 1242 - 1249

[8] Schroder D. K. (1997). IEEE Trans. Electron Device, ED - 44, 160 